\title{
Estudo experimental e modelagem de lagoa de detenção em Brasília - DF: comportamento no amortecimento de cheias
}

\section{Experimental study and modeling of detention pond in Brasília -DF: behavior in flood damping.}

Data de entrada: $19 / 08 / 2019$

Data de aprovação: 24/03/2020
ORCID ID

Paula ACV (D) https://orcid.org/0000-0003-4144-9616
Costa MEL (D) https://orcid.org/0000-0002-5477-4349

Koide S (iD https://orcid.org/0000-0002-0424-5748

\section{Resumo}

A ocupação do espaço urbano ocasiona, em geral, o aumento das áreas impermeabilizadas e a aceleração do escoamento para jusante, provocando maiores picos de vazão e volumes escoados superficialmente. De forma a minimizar os efeitos das cheias urbanas, várias medidas vêm sendo adotadas e, dentre elas, destacam-se as lagoas de detenção. No presente trabalho, teve-se por objetivo avaliar o comportamento da lagoa de detenção inserida no Parque Ezechias Heringer, na Região Administrativa do Guará/DF, por meio de monitoramento e modelagem utilizando o programa SWMM por meio da interface do PCSWMM, buscando avaliar a eficiência da lagoa quanto ao amortecimento dos picos de vazões. $O$ afluente para a lagoa de detenção é oriundo de sistema convencional de drenagem urbana com $7,65 \mathrm{~km}^{2}$ de área de contribuição. A lagoa apresentou eficiência média de redução dos picos de cheia de $95,5 \%$, mostrando-se capaz de receber maior volume de águas pluviais de áreas adjacentes ainda não atendidas.

Palavras-chave: Drenagem urbana sustentável. Onda de cheia. Monitoramento.

\section{Abstract}

The occupation of the urban space usually causes an increase of impervious areas and the acceleration of downstream flow, causing larger peak flows and volumes drained superficially. In order to minimize the effects of urban flooding, several measures have been adopted, including detention ponds. The objective in this study is to evaluate the behavior of the detention pond inserted in the Ezechias Heringer Park, in the administrative region of Guarál DF, by monitoring and modeling, using the SWMM program through the PCSWMM interface, aiming to evaluate the pond efficiency in damping outflow peaks. The inflow to the detention pond is generated by a conventional urban drainage system with $7.65 \mathrm{~km}^{2}$ of contribution area. The pond presented an average efficiency of $95.5 \%$ in terms of peakflow reduction, being able to receive higher volume of rainwater from adjacent areas not yet served

Keywords: Sustainable urban drainage. Flood wave. Monitoring.

\footnotetext{
${ }^{1}$ Universidade de Brasília (UnB) - Brasília - Distrito Federal - Brasil.

"Autora correspondente: anacarolvp93agmail.com.
} 


\section{INTRODUÇÃO}

O aumento da urbanização, caracterizado principalmente pela impermeabilização desordenada do solo da bacia de drenagem, bem como os efeitos das mudanças climáticas, têm contribuído de modo significativo para o aumento do escoamento superficial, gerando cada vez mais estresse aos sistemas convencionais de drenagem pluvial (ECKART, MCPHEE e BOLISETTI, 2017).

Com o intuito de minimizar os efeitos das inundações em áreas urbanas e minimizar os impactos sobre os corpos hídricos receptores, várias medidas de controle vêm sendo estudadas e adotadas. Dentre elas, citam-se as lagoas de detenção, medidas estruturais de manejo de águas pluviais, que são utilizadas com frequência em áreas com urbanização consolidada.

As lagoas de detenção são obras destinadas tanto ao amortecimento dos picos de cheias, por meio da reservação de parte do volume escoado superficialmente, como à remoção de detritos e poluentes carreados pelos escoamentos, podendo apresentar também funções paisagísticas e recreativas, com o devido monitoramento da qualidade da água.

Há, comumente, uma distinção entre lagoas de detenção e retenção por suas finalidades e também pela disposição e operação de seus elementos de descarga. Em princípio, as bacias de retenção devem manter as águas de drenagem armazenadas por um período maior, de forma a promover a melhora da qualidade da água por meio da sedimentação de partículas em suspensão. Os dispositivos de saída, durante o evento chuvoso, devem reter a maior parte do escoamento e, preferencialmente, realizar a descarga pela superfície. As lagoas de detenção, por sua vez, têm finalidade apenas de amortecer os picos de vazão e, portanto, os dispositivos de saída são dimensionados para que as vazões de descarga não ultrapassem valores pré-determinados durante eventos críticos com certo período de recorrência (BAPTISTA, NASCIMENTO e BARRAUD, 2011).

Os modelos computacionais são ferramentas muito úteis no gerenciamento das águas pluviais urbanas. Podem ser utilizados na fase de planejamento e de detalhamento de projeto, no caso de manutenção corretiva em que seja necessário realizar obras complementares e na simulação de cenários para a avaliação do comportamento de um sistema de drenagem submetido a determinadas condições de precipitação e uso e ocupação do solo (RIGHETTO, 2009; CANHOLI, 2014).

A realização de uma modelagem precisa contribui para um melhor entendimento do funcionamento das estruturas em estudo, no caso, bacias de detenção, reduzindo custos de monitoramento e auxiliando no desenvolvimento de designs futuros mais eficientes (TROITSKY et al., 2019).

O modelo hidráulico-hidrológico empregado neste estudo foi o Storm Water Management Model (SWMM), que simula eventos chuvosos reais com base em dados de precipitação (hietograma) e outras informações meteorológicas, além de considerar as características do sistema (captação, transporte, armazenamento/tratamento) e da bacia hidrológica para prever os resultados relativos à quantidade e à qualidade do escoamento (HUBER e DICKINSON, 1992). Consiste num modelo distribuído, de simulação temporal discreta, onde a bacia hidrográfica é representada por um conjunto de sub-bacias hidrográficas e canais/condutos (BELING, 2013).

SOUZA, COSTA e KOIDE (2019) monitoraram as vazões e qualidade da água em uma rede de drenagem em Brasília - DF e, utilizando o modelo SWMM, realizaram a calibração das vazões obtendo um bom ajuste, com coeficientes de determinação $\left(R^{2}\right)$ e Nash-Sutcliffe (NSE) iguais a 0,90 e 0,94 , respectivamente. 0 modelo foi então utilizado na avaliação de diferentes combinações 
de lagoas de detenção na bacia. As lagoas alocadas próximas ao exutório se mostraram mais eficientes no abatimento das vazões de pico.

TSUJI, COSTA e KOIDE (2019) aplicaram o modelo SWMM para simulação das vazões em sub-bacia urbana inserida na Bacia Hidrográfica do Lago Paranoá. Nesse estudo, verificou-se que o SWMM representa bem eventos cuja precipitação apresenta distribuição espacial uniforme na área de contribuição, obtendo-se bom ajuste após a calibração com valores de NSE e $\mathrm{R}^{2}$ equivalentes a 0,82 e 0,84 , respectivamente.

\section{OBJETIVO}

Este trabalho tem por objetivo avaliar a capacidade de amortecimento da lagoa de detenção inserida no Parque Ezechias Heringer, na cidade satélite do Guará - DF, por meio de monitoramento hidrológico, e comparar os resultados obtidos com a modelagem utilizando o programa SWMM por meio da interface PCSWMM.

\section{MATERIAIS E MÉTODOS \\ 3.1 Área de Estudo}

A área de estudo encontra-se inserida na Bacia Hidrográfica do Lago Paranoá, no Distrito Federal, entre as unidades hidrográficas do Riacho Fundo e Lago Paranoá (Fig. 1). A área drenada para a lagoa de detenção possui $7,65 \mathrm{~km}^{2}$. A lagoa de detenção, por sua vez, está localizada no Parque Ezechias Heringer, na Região Administrativa do Guará - DF, e apresenta área de aproximadamente 24,6 ha.

A lagoa de detenção foi implantada na área de lagoas de estabilização desativadas pela Companhia de Saneamento Ambiental do Distrito Federal - CAESB, tendo sido realizadas obras para adequar a área. A lagoa de estabilização de esgoto que antes ocupava a área foi desativada em 1993, quando a Estação de Tratamento de Esgotos Brasília Sul (ETE Sul) entrou em funcionamento. A obra da lagoa de detenção em estudo foi finalizada em janeiro de 2007.

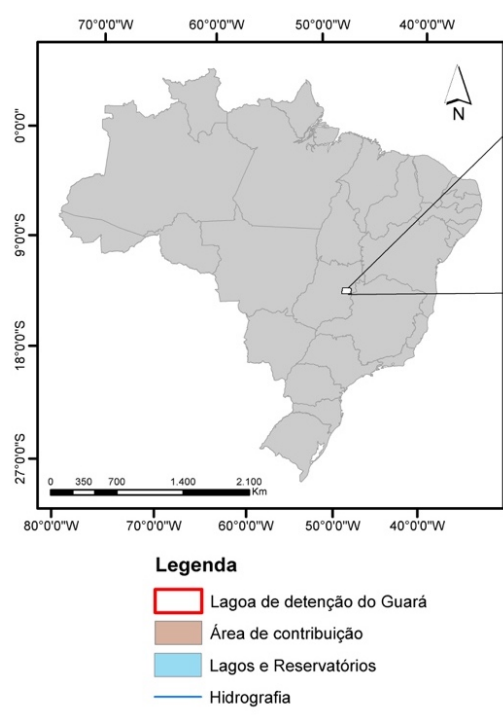

Figura 1 - Localização da lagoa de detenção do Guará e sua área de contribuição.

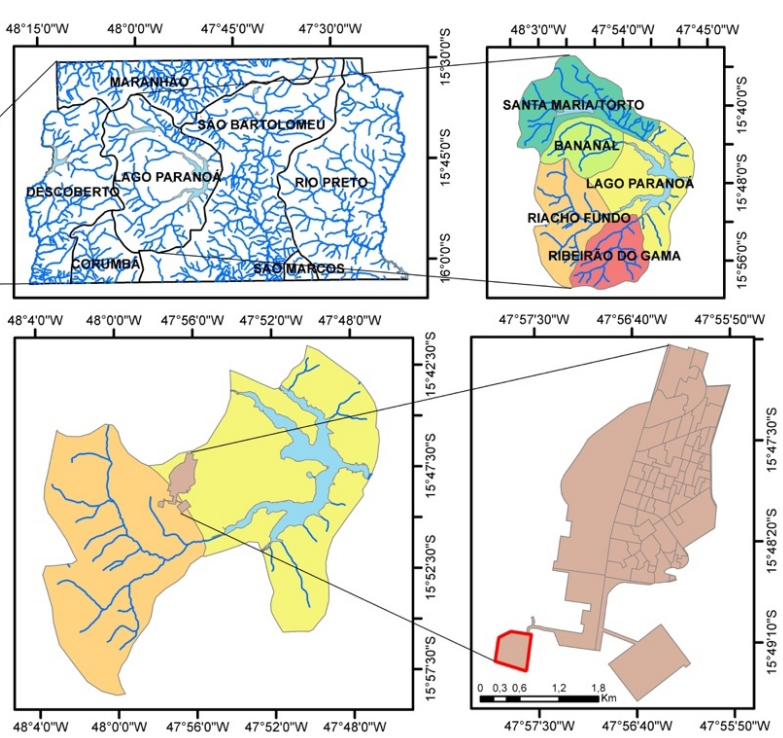


O trecho final da galeria de entrada na bacia de detenção é dividido por septos paralelos, formando três subgalerias de $2,7 \times 2,5$ m de seção. A estrutura de saída da bacia consiste em um vertedor de $20 \mathrm{~m}$ de comprimento e uma descarga de fundo de $1 \mathrm{~m}$ de diâmetro. A cota de fundo de projeto da lagoa é $1079 \mathrm{~m}$, e a cota da crista do barramento, $1081 \mathrm{~m}$. Após a detenção na bacia, o lançamento é realizado no córrego Guará, afluente do córrego Riacho Fundo, por meio de uma tubulação de 1,5 m de diâmetro (Fig. 2).

A área que contribui para a lagoa de detenção do Guará abrange tanto regiões residenciais como comerciais e industriais, apresentando, em geral, boa arborização.

\subsection{Monitoramento}

O monitoramento foi realizado entre os meses de outubro de 2018 a março de 2019. Para a medição da precipitação, realizou-se a instalação de cinco pluviógrafos de báscula, modelo RG3-M, na área de estudo. Além disso, utilizaram-se também dados de precipitação fornecidos pela Agência Nacional de Águas - ANA e pelo Instituto Nacional de Meteorologia - INMET, de estações pluviométricas monitoradas por esses órgãos.
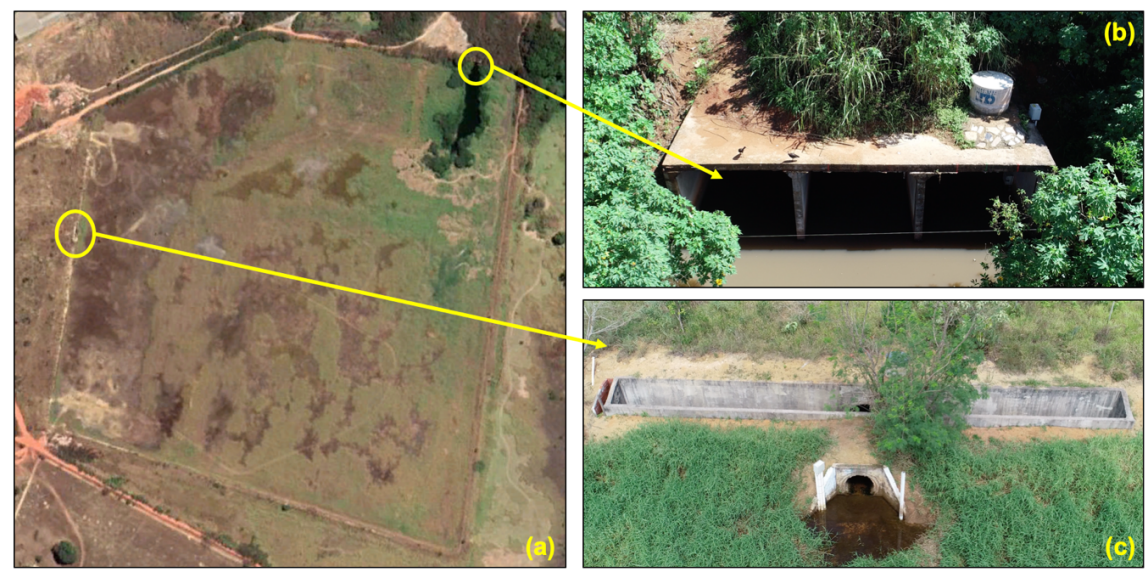

Figura 2 - (a) Lagoa de detenção do Guará com foco na localização das estruturas de entrada e saída;

(b) Galeria de entrada; (c) Vertedor e descarga de fundo na saída. Fonte: Autor.
Para o monitoramento fluviométrico da lagoa de detenção do Guará, realizou-se a instalação de dois linígrafos de boia, sendo um localizado na galeria de entrada da lagoa e o outro próximo ao orifício de fundo na saída da estrutura. Foi instalado, também, um linígrafo de pressão próximo ao vertedor, com sensor no fundo da lagoa, com o objetivo de monitorar o nível no caso de vertimento, quando o linígrafo de boia ficaria inacessível. Realizou-se, também, a instalação de três réguas linimétricas, uma para cada linígrafo, sendo locadas nas proximidades desses.

Para a determinação das vazões de entrada e saída da lagoa de detenção nos eventos de precipitação, utilizaram-se os dados obtidos pelos linígrafos e as curvas-chave da galeria e da descarga de fundo. As curvas-chave foram construídas a partir da medição de vazões para diferentes cotas tanto na entrada como na saída da lagoa.

Para as medições de vazão na galeria de entrada e na descarga de fundo, utilizou-se o equipamento ADC (Acoustic Digital Current meter) da marca OTT, que determina a velocidade do fluxo por meio de efeito Doppler. 
$\mathrm{Na}$ galeria de entrada, as medições de velocidade utilizand o o ADC foram feitas em três verticais para cada uma das subgalerias, a $60 \%$ da profundidade indicada pela régua linimétrica. As verticais foram espaçadas igualmente em 0,675 m. No momento da passagem da onda de cheia pelo canal, devido à rápida alteração dos valores de cota, optou-se por realizar a medição somente na vertical central do septo do meio. Foram realizadas medições de vazão in loco para dois eventos chuvosos, o do dia 26/01/2019 e o do dia 08/02/2019.

Quanto às medições de velocidade na saída da lagoa de detenção, dividiu-se a seção transversal da descarga de fundo em sete verticais espaçadas igualmente em 0,125 m. Em cada uma das verticais, realizou-se a medição da velocidade do fluxo com o ADC em 20, 40, 60 e $80 \%$ da profundidade marcada pela régua linimétrica. Dessa forma, foi possível determinar a velocidade média para cada vertical, sendo essa multiplicada pela área de influência da vertical correspondente para a obtenção da vazão parcial da respectiva vertical. A vazão total, para uma determinada cota, consiste no somatório das vazões parciais calculadas. As medições das vazões na saída puderam ser mais detalhadas, uma vez que a variação de nível era mais lenta.

\subsection{Modelagem Matemática}

Para a modelagem matemática das vazões utilizou-se o modelo SWMM por meio da interface do software PCSWMM. O modelo de infiltração adotado para as simulações foi o da Curva Número do SCS. Para o método de transporte, isto é, método de escoamento na rede de drenagem, adotou-se o modelo da onda dinâmica, por apresentar uma resolução completa das equações de Saint-Venant, importante, no caso, em função da baixa declividade do trecho final da galeria.
A área de contribuição foi dividida em 677 subbacias, interligadas por 1219 condutos e 1215 poços de visita. Realizou-se a representação da lagoa de detenção, da descarga de fundo e do vertedor no modelo. Utilizou-se o método dos polígonos de Thiessen, tendo como base a localização dos pluviógrafos instalados em campo, para a definição e caracterização da distribuição espacial da chuva nas sub-bacias do modelo.

Adotou-se valor inicial de rugosidade para os condutos de 0,015. O valor inicial para armazenamento em depressões de áreas permeáveis foi definido como sendo equivalente à abstração inicial $\left(l_{\mathrm{a}}\right)$ do $S C S$, ou seja, $I_{a}=0,2 \cdot S$, em que o $S$ é determinado pela Eq. 1. Seguindo recomendação de ROSSMAN e HUBER (2016), o coeficiente de rugosidade de áreas permeáveis foi adotado como 0 , de maneira a prevenir atraso no fluxo do escoamento superficial.

$$
S=\frac{25400}{C N}-254
$$

Em que:

$\mathrm{S}$ - Potencial máximo de retenção $(\mathrm{mm})$;

$\mathrm{CN}$ - Curva Número.

Por recomendação do modelo, como neste estudo foi realizado um cálculo médio do $\mathrm{CN}$ para cada sub-bacia, não foram atribuídas porcentagens de áreas impermeáveis a essas; caso contrário, o modelo contabilizaria em duplicidade as áreas impermeáveis. Isso se dá porque o programa somente aplica os modelos de infiltração (SCS, Horton e Green-Ampt) às áreas permeáveis (JAMES, ROSSMAN e JAMES, 2010).

\section{RESULTADOS E DISCUSSÃO}

\subsection{Dados de Precipitação}

O clima do Distrito Federal é caracterizado pela forte sazonalidade, apresentando dois períodos 
distintos bem definidos. O período entre maio e setembro é caracterizado por baixas taxas de precipitação. Já a estação chuvosa está compreendida entre os meses de outubro a abril, sendo que os meses de dezembro a março concentram quase metade da precipitação total anual para a região (CAMPOS, 2004).

Tendo como base a normal climatológica 19611990 para a cidade de Brasília, pode-se observar pela Fig. 3 que, enquanto os meses de outubro e novembro excederam a média histórica, os meses de janeiro e fevereiro apresentaram volumes de chuva abaixo do esperado. Em todos os pluviógrafos analisados, o mês de janeiro apresentou acumulado mensal inferior a $50 \mathrm{~mm}$ de chuva, muito abaixo dos $247,4 \mathrm{~mm}$ da normal climatológica para o mesmo mês.

As instalações dos cinco pluviógrafos monitorados por esse projeto foram realizadas durante o mês de outubro de 2018 e, por esse motivo, os dados dos respectivos equipamentos para esse mês em específico não se encontram na Fig. 3.

Ainda com relação à Fig. 3 observa-se que, em geral, existe uma variabilidade espacial significativa das precipitações na área de estudo. No mês de novembro, a maior diferença foi de $89,2 \mathrm{~mm}$, sendo o maior acumulado mensal registrado no pluviógrafo instalado no Cruzeiro Novo e, o menor, no equipamento localizado na lagoa de detenção do Guará. Já no mês de dezembro, a maior variação foi de $117,8 \mathrm{~mm}$, quando o equipamento da ANA registrou o maior volume mensal acumulado e o pluviógrafo da Octogonal, o menor.

Para a determinação dos tempos de retorno dos eventos observados ao longo do período de monitoramento deste estudo, utilizou-se a equação da curva IDF (Intensidade-Duração-Frequência) de Brasília adotada pelo Plano Diretor de Drenagem Urbana - PDDU (GDF, 2009), apresentada na Eq. 2. A determinação do tempo de retorno ou recorrência é de grande relevância, pois indica o intervalo médio, em anos, no qual um determinado evento deve ser igualado ou superado. 0 conceito desse termo está associado à frequência e, consequentemente, à probabilidade de superação de um determinado valor. $A$ análise do tempo de recorrência, portanto, é um indicativo da magnitude dos eventos.

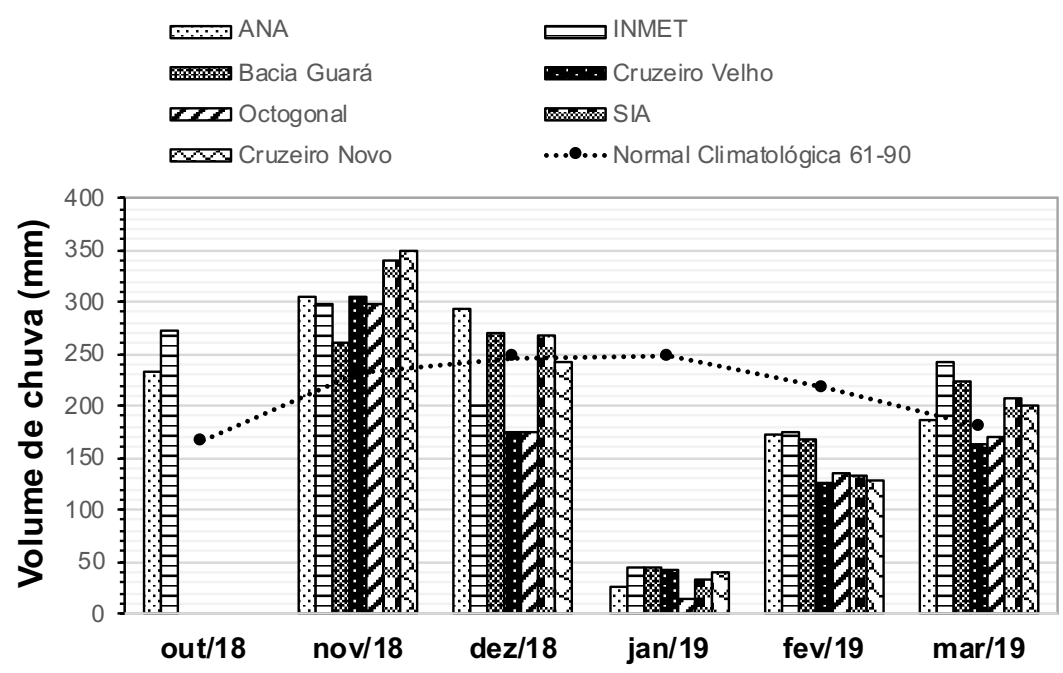

Figura 3 - Comparação do acumulado mensal de chuva em cada um dos pluviógrafos da área de estudo para os meses de outubro/2018 a março/2019. Fonte: Autor 


$$
i=\frac{1574,7 \cdot T_{r}^{0,207}}{(D+11)^{0,884}}
$$

Em que:

i - Intensidade da precipitação $\left(\mathrm{mm} \cdot \mathrm{h}^{-1}\right.$ );

$\mathrm{T}_{\mathrm{r}}$ - Tempo de retorno (anos);

D - Duração da chuva (minutos).

Durante todo o período monitorado, foram observados, aproximadamente, 70 eventos chuvosos, dentre os quais apenas três apresentaram tempo de retorno igual ou superior a 1 ano, os três ocorreram no mês de dezembro. 0 evento de maior destaque ocorreu no dia 08/12/2018, com 60 min de duração e apresentou tempo de retorno de 11,8 anos, seguido do evento do dia 26/12/2018, com duração de 160 min e 4,8 anos de tempo de retorno, e do evento do dia $31 / 12 / 2018$, que apresentou $100 \mathrm{~min}$ de duração e 1 ano de tempo de retorno.

É importante ressaltar que, em geral, as obras de drenagem são projetadas para período de retorno de 10 anos, ou seja, chuvas intensas como a do dia 08/12/2018 geram sobrecarga aos sistemas de drenagem, causando inundações e transtornos à população. Verificou-se, também, que a média de intensidade das precipitações monitoradas na área de estudo entre 2018-2019 correspondeu a $7,9 \mathrm{~mm} \cdot \mathrm{h}^{-1}$.

\subsection{Dados de Vazão}

Devido ao acúmulo de água parada na entrada da lagoa associado às baixas declividades do trecho final da rede de drenagem, verificou-se a ocorrência de remanso na galeria de entrada da lagoa, o que dificultou a elaboração de uma curva-chave representativa para todas a cotas e vazões. Durante todo o período do estudo, incluindo o período de estiagem, a galeria de entrada da lagoa apresentou lâmina de água em seu interior. A menor cota observada foi de
$28 \mathrm{~cm}$ em 07/09/2018. As estruturas de dissipação de energia existentes na entrada da lagoa ficaram submersas durante todo o período analisado.

SEFIONE (2002) afirma que o efeito de remanso, fenômeno que ocorre quando o escoamento de montante sofre influência pelo escoamento de jusante, é uma das causas para o chamado laço na curva-chave. A curva-chave em laço ocorre quando há uma relação não-unívoca entre cotas e vazões, ou seja, quando são verificadas diferentes vazões para uma mesma cota, como mostrado na Fig. 4. A curva em regime uniforme representa a relação biunívoca, onde cada cota corresponde a uma única vazão e vice-versa.

Ainda de acordo com SEFIONE (2002), a passagem de uma onda de cheia num trecho de rio com baixa declividade, onde no momento ascensional a vazão é maior, bem como a existência de seções ou controles instáveis e controle de jusante variável, são outros fatores que provocam o laço na curva-chave.

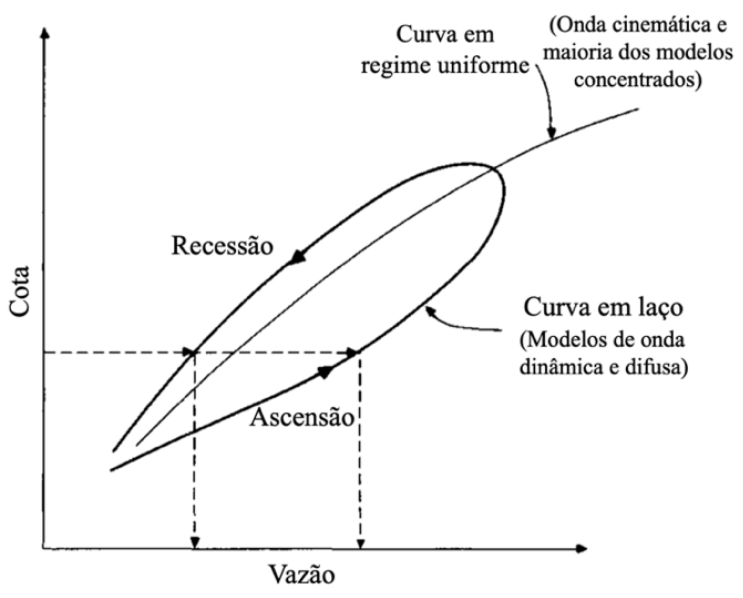

Figura 4 - Curva-chave em laço (Adaptado de CHOW, MAIDMENT e MAYS, 1988).

Nesse sentido, tendo-se verificado a ocorrência de vazões distintas para uma mesma cota na galeria de entrada da lagoa de detenção, a depender da fase de ascensão ou de recessão, realizou-se a elaboração de duas curvas-chave para o canal, 
sendo uma representativa do ramo ascendente, com vazões mais elevadas, e, a outra, do ramo descendente, com vazões menores. No entanto, sabe-se que essas curvas podem ser muito variáveis em função das características das ondas de cheia, podendo formar diferentes laços (CHOW, MAIDMENT e MAYS, 1988).

O resultado da curva-chave para a galeria de entrada pode ser visualizado na Fig. 5. É válido ressaltar que foi realizada a extrapolação superior da curva-chave, tanto para o ramo ascendente como para o descendente, por meio do método de Stevens, devido ao fato de o canal apresentar seção transversal contínua e uniforme.

Pelo fato de o nível na saída da lagoa ser mais estável do que na galeria de entrada, foi possível realizar as medições de velocidade na descarga de fundo em várias verticais e profundidades. Devido à lenta e gradual liberação da água para jusante, foram necessárias diversas campanhas de medição de vazão in loco na saída, de forma a obter dados de velocidade em diferentes cotas. A curva-chave determinada para a descarga de fundo da saída da lagoa de detenção é apresentada na Fig. 6.

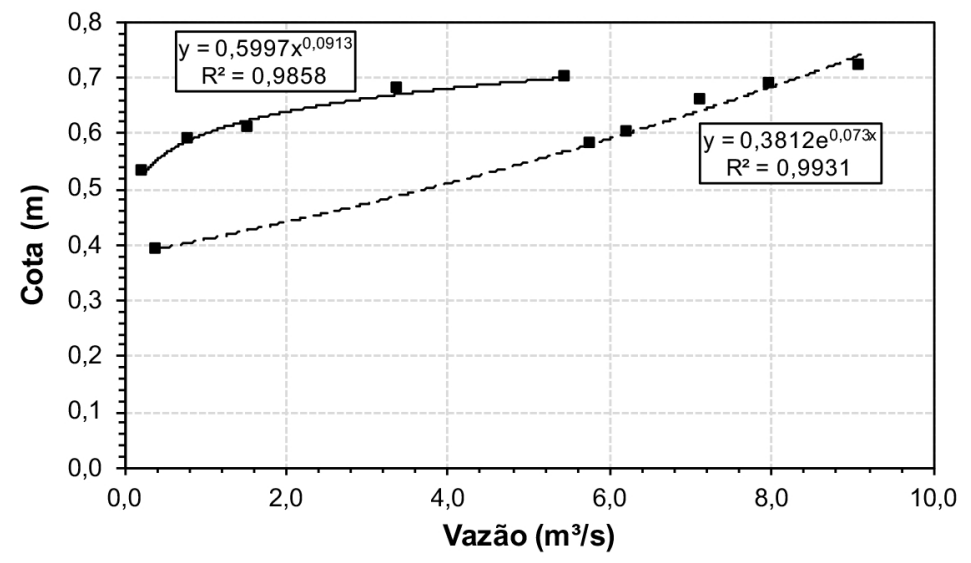

Figura 5 - Curva-chave determinada para a galeria de entrada da lagoa de detenção, onde o ramo ascendente corresponde à linha tracejada e, o descendente, à linha contínua.

Fonte: Autor

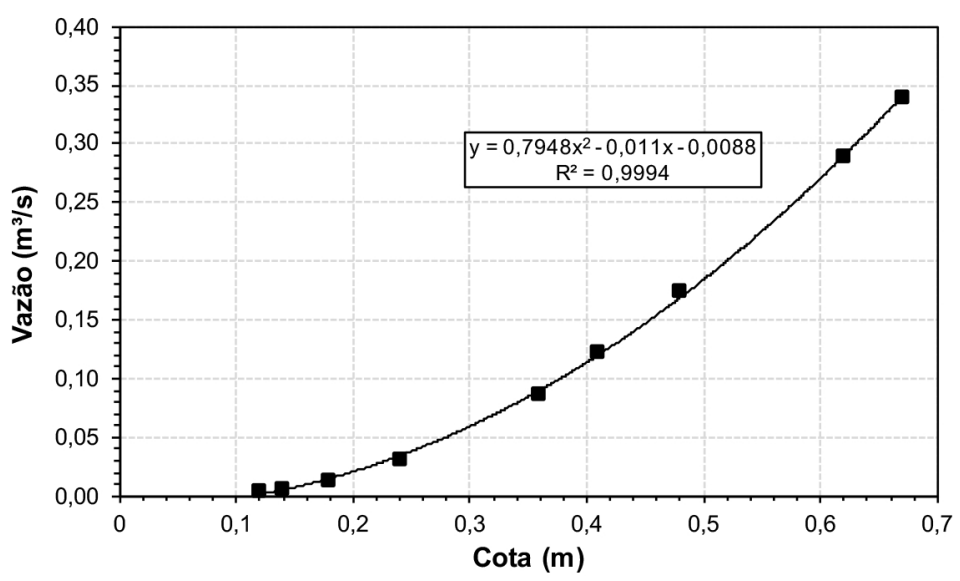

Figura 6 - Curva-chave determinada para a descarga de fundo na saída da lagoa de detenção. Fonte: Autor 
A partir das curvas-chave mostradas anteriormente, associadas aos dados dos linígrafos instalados na entrada e saída da estrutura em análise, foi possível estimar as vazões ao longo do tempo, possibilitando a construção dos hidrogramas observados no período monitorado.

Os hidrogramas de entrada e saída da lagoa de detenção podem ser visualizados nas Fig. 7 e 8, respectivamente. A vazão máxima observada na galeria de entrada durante o período monitorado correspondeu a $15,4 \mathrm{~m}^{3} \cdot \mathrm{s}^{-1}$ referente ao evento do dia 08/12/2018 às $17 \mathrm{~h} 47$, com cota de aproximadamente $91 \mathrm{~cm}$.

A maior vazão observada na saída da lagoa de detenção do Guará também ocorreu no dia $08 / 12 / 2018$, por volta das $23 \mathrm{~h}$, correspondendo a
$1,27 \mathrm{~m}^{3} \cdot \mathrm{s}^{-1}$ e cota de $127,8 \mathrm{~cm}$, não sendo verificado, portanto, extravasamento por meio do vertedor de saída, tendo em vista que esse se encontra a 1,5 $\mathrm{m}$ do fundo da lagoa. Para esse evento, portanto, percebe-se que a lagoa de detenção em estudo apresentou eficiência de amortecimento de $91,8 \%$.

Analisando os eventos do período monitorado, observou-se um abatimento médio do pico de vazão de 95,5\% pela lagoa de detenção do Guará, mostrando, portanto, a eficiência hidráulica dessa na redução dos picos de cheia, liberando de forma gradual a água armazenada em seu interior para jusante. Esse elevado abatimento é decorrente do grande tamanho da lagoa de detenção, o que promove, consequentemente, uma maior capacidade de amortecimento de vazões.

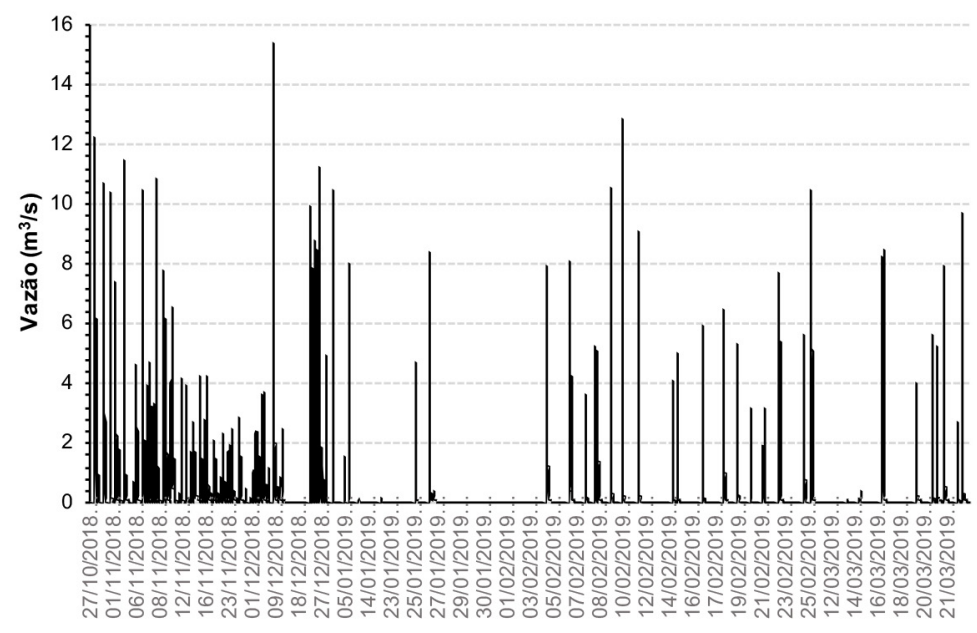

Figura 7 - Hidrograma na galeria de entrada da lagoa de detenção do Guará para todo o período monitorado. Fonte: Autor

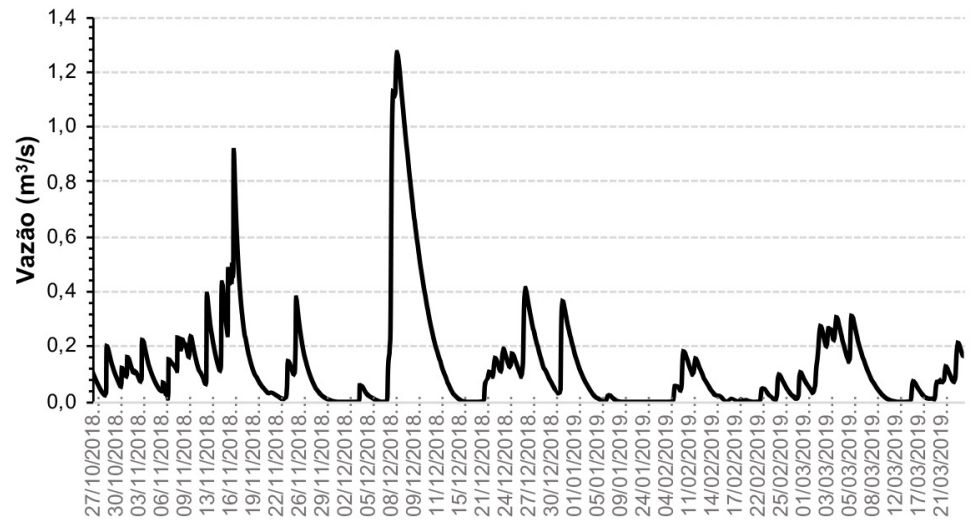

Figura 8 - Hidrograma na estrutura de saída da lagoa de detenção do Guará para todo o período monitorado. Fonte: Autor 
CAMPANA, BERNARDES e SILVA (2007) verificaram, para todos os eventos monitorados no estudo, redução média da vazão de pico de $62,6 \%$ para uma bacia de detenção seca e de $74 \%$ para uma bacia de detenção alagada, ambas localizadas em Brasília - DF. A bacia de detenção alagada, que apresentou maior taxa de abatimento, possui 16,7 ha de área, com $0,68 \mathrm{~m}$ de profundidade média, e recebe o escoamento de uma área de drenagem de $6,12 \mathrm{~km}^{2}$.

Por meio dos hidrogramas, verificou-se que a lagoa de detenção do Guará leva aproximadamente 7 dias para descarregar um evento chuvoso intenso. Esse acúmulo de água por dias consecutivos pode contribuir para a proliferação de animais transmissores de doenças, mas também colabora para melhoria da qualidade da água pluvial devido ao maior tempo de residência no interior da lagoa.

Após análise dos dados dos linígrafos, verificouse que o tempo entre os picos de vazão de entrada e saída varia de forma significativa, sendo observados valores entre $1 \mathrm{~h}$ e $8 \mathrm{~h}$ de duração. Essa constatação é indício da ocorrência de caminhos preferenciais no interior da lagoa bem como da influência da vegetação no retardo do escoamento.

Por meio da Resolução $n^{\circ}$ 9, de 08 de abril de 2011, a Adasa determinou que o lançamento de águas pluviais em corpo hídrico superficial não deve ultrapassar a vazão específica de $24,4 \mathrm{~L} \cdot \mathrm{s}^{-1} \cdot \mathrm{ha}^{-1}$. Para a área em estudo, que apresenta $7,65 \mathrm{~km}^{2}$, essa vazão corresponderia a $18,67 \mathrm{~m}^{3} \cdot \mathrm{s}^{-1}$, valor esse bem maior do que de fato é lançado pela lagoa de detenção no córrego Guará, visto que a máxima vazão de saída observada durante o período monitorado correspondeu a $1,27 \mathrm{~m}^{3} \cdot \mathrm{s}^{-1}$. Além disso, levando em consideração o fato de que a lagoa de detenção do Guará não sofreu extravasamento por meio do vertedor de saída no período em análise, pode-se dizer que a estrutura está subutilizada, sendo capaz de atender área de contribuição maior.

É importante ressaltar que a Resolução $n^{\circ}$ 9/2011, abordada anteriormente, foi estabelecida posteriormente à construção da lagoa de detenção em estudo. Porém, a verificação da adequação ao limite estabelecido pela resolução permanece válida, permitindo avaliação da capacidade de amortecimento da estrutura.

Ainda de acordo com a Resolução no 9/2011, essa aborda a implementação de reservatórios de qualidade seguidos de reservatórios de quantidade, dispostos em série, como forma de promover a preservação do corpo hídrico receptor. Seguindo as diretrizes da resolução, o volume de um reservatório de qualidade é determinado conforme a Eq. 3:

$V_{q a}=\left(33,8+1,80 \cdot A_{i}\right) \cdot A_{c}$

em que $V_{\text {qa }}$ é o volume em $\mathrm{m}^{3}, \mathrm{~A}_{\mathrm{i}}$ é o percentual de área impermeável do terreno, $A_{c}$ corresponde a área de contribuição em ha. Considerando que aproximadamente $50 \%$ da área de estudo é impermeabilizada e que a altura do reservatório corresponde a $2 \mathrm{~m}$, obtém-se área de reservatório de qualidade equivalente a 1,3 ha. Para o dimensionamento de reservatório de quantidade, nos casos em que a área de contribuição é superior a 200 ha, como é o caso da área abordada neste estudo, a resolução exige a elaboração de estudo hidrológico para a determinação do volume do reservatório de detenção e de seus dispositivos de saída. Esse estudo, de acordo com a resolução, deve considerar a utilização de modelo hidrológico chuva-vazão com chuva de 10 anos de tempo de retorno e duração mínima de 24 horas.

VOLKEN (2018) realizou esse estudo hidrológico para a lagoa de detenção do Guará por meio de 
modelagem com o programa PCSWMM para analisar qual deveria ser o tamanho da estrutura com base nas diretrizes da Resolução nº 9/2011. Foi constatado que, nos termos da resolução, o volume necessário para a lagoa seria de $267.500 \mathrm{~m}^{3}$, o que levaria a uma área aproximada de 13,4 ha, considerando altura de $2 \mathrm{~m}$. Realizando o somatório das áreas necessárias para os reservatórios de qualidade e quantidade, obtém-se 14,7 ha, valor esse correspondente a $59,8 \%$ da verdadeira área da lagoa de detenção em estudo. Percebese, portanto, que a lagoa de detenção do Guará encontra-se superdimensionada e pode ser utilizada para atender ao amortecimento de cheias e de melhoria da qualidade da água de outras áreas adjacentes, ainda não atendidas.

A construção de barreiras de forma a promover maior tempo de residência no interior da estrutura pode promover melhoria substancial da qualidade da água. Pelo tamanho da área, seria possível até mesmo prever mecanismos para remoção de óleos e graxas, tendo em vista afluentes à lagoa oriundos de áreas industriais e de oficinas mecânicas.

\subsection{Modelagem matemática chuva-vazão}

Quanto à modelagem chuva-vazão, realizou-se a calibração do modelo com base no evento do dia $31 / 12 / 2018$, por suas características de ser um evento isolado e espacialmente mais uniforme. Esse evento apresentou intensidade média de $14,5 \mathrm{~mm} \cdot \mathrm{h}^{-1}$ e duração aproximada de $100 \mathrm{~min}$. Para a entrada da lagoa, os valores de NSE e $\mathrm{R}^{2}$ para a modelagem sem calibração corresponderam a 0,59 e 0,65, respectivamente. Já para a saída, os resultados de NSE e $\mathrm{R}^{2}$ não foram bons, correspondendo respectivamente a -13,7 e 0,16.

$\mathrm{Na}$ calibração, foram alterados parâmetros como largura, armazenamento em depressões permeáveis, Curva Número e rugosidade dos condutos da rede de drenagem, sendo os três últimos os que apresentaram maior sensibilidade, promovendo alterações significativas ao hidrograma simulado. As incertezas atribuídas a cada parâmetro, no momento da calibração, foram definidas com base no proposto por TSUJI (2018). A Tabela 1 apresenta as incertezas que foram associadas a cada um dos parâmetros do modelo selecionados para a calibração bem como as alterações que de fato foram feitas. As incertezas estão relacionadas ao grau de confiabilidade na determinação ou obtenção do valor de um determinado parâmetro ou atributo. A largura das sub-bacias e o armazenamento em depressões permeáveis, por exemplo, são parâmetros de difícil mensuração/definição e, por esse motivo, são atribuídos a eles elevadas incertezas.

Tabela 1 - Incertezas associadas aos parâmetros e alterações feitas na calibração.

\begin{tabular}{|c|c|c|}
\hline Parâmetros & Incertezas & Alterações \\
\hline Largura das sub-bacia (Width) & $50 \%$ & $(+) 50 \%$ \\
\hline Área das sub-bacias (Area) & $5 \%$ & 0 \\
\hline Declividade (Slope) & $5 \%$ & 0 \\
\hline $\begin{array}{c}\text { Armazenamento em depressões } \\
\text { permeáveis (Dstore Perv) }\end{array}$ & $50 \%$ & $(+) 50 \%$ \\
\hline Curva Número (CN) & $10 \%$ & $(+) 1,5 \%$ \\
\hline Rugosidade dos condutos (Roughness) & $20 \%$ & $(+) 14,4 \%$ \\
\hline
\end{tabular}

Após calibração, os novos valores de NSE e $\mathrm{R}^{2} \mathrm{da}$ entrada para o evento do dia 31/12/2018 corresponderam a 0,62 e 0,72, respectivamente, enquanto os da saída foram de $-7,32$ e 0,28 . As Fig. 9 e 10 apresentam os hidrogramas simulados sem calibração e após calibração bem como o hidrograma observado em campo para a entrada e saída da lagoa de detenção, respectivamente. Percebe-se que, apesar dos resultados estatísticos satisfatórios para a entrada, o formato do hidrograma modelado permanece distinto do observado, podendo associar esse fato à curva-chave e à existência de remanso no interior da galeria de entrada. 
Pela Fig. 10, observa-se que a vazão observada permanece subestimada em relação à modelada. Percebe-se também que o decaimento da vazão modelada é mais acelerado em comparação ao observado, talvez em função de não se ter levado em conta, na modelagem, a existência de vegetação, sedimentos e volumes mortos no interior da estrutura, o que reduz o volume disponível e pode alterar o comportamento hidráulico do fluxo no interior da lagoa, considerada na modelagem como um reservatório com superfície horizontal.

Em seguida, realizou-se a verificação da modelagem para alguns eventos chuvosos, mostrados na Tabela 2, onde são apresentados somente os parâmetros estatísticos para a entrada da estrutura.
Percebe-se pela Tabela 2 que, apesar dos bons resultados de $\mathrm{R}^{2}$, não se obtiveram valores de NSE satisfatórios, com exceção do evento do dia $15 / 11 / 2018$. Acredita-se que melhores valores para os parâmetros estatísticos serão obtidos após a obtenção de curva-chave mais representativa para a galeria de entrada, com melhor compreensão do fenômeno de remanso que lá ocorre. Para isso, sugere-se, para trabalhos futuros, a instalação, no interior da galeria, de equipamento de medição contínua de velocidade como, por exemplo, o H-ADCP, que mede a velocidade do fluxo ao longo da seção transversal do canal por meio de efeito Doppler, de maneira a obter dados mais precisos de vazão na entrada da lagoa.

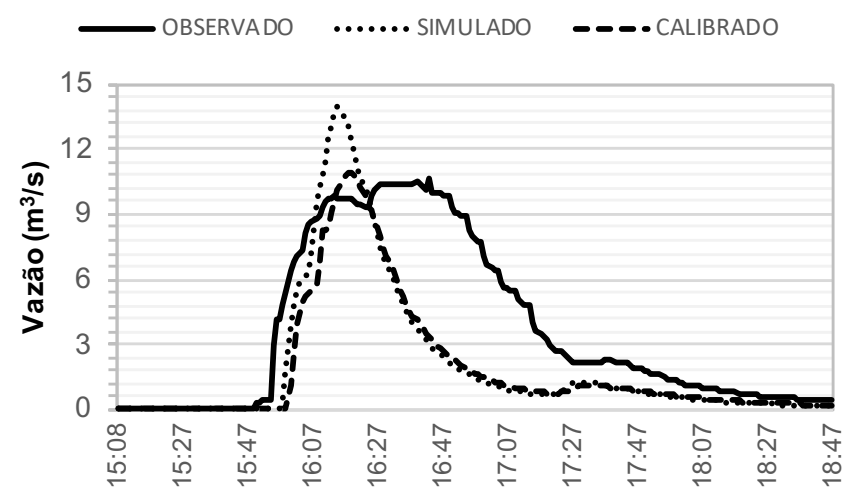

Figura 9 - Comparação entre os hidrogramas da entrada da lagoa para o evento do dia 31/12/2018. Fonte: Autor

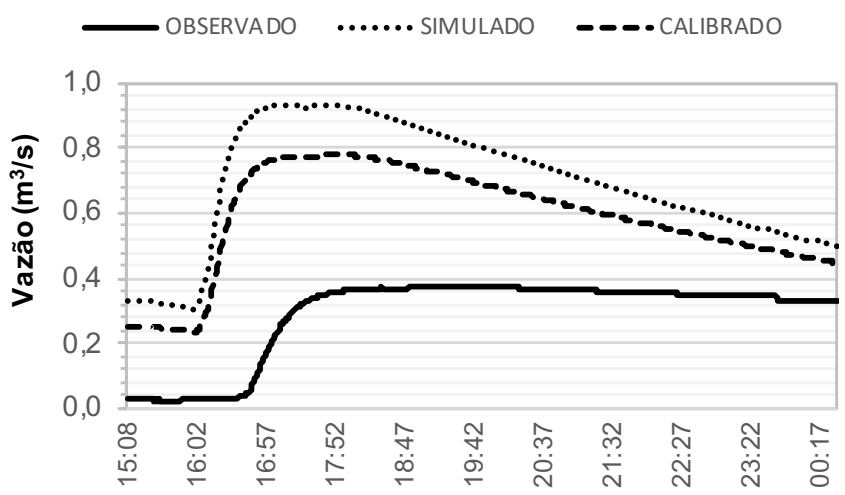

Figura 10 - Comparação entre os hidrogramas da saída da lagoa para o evento do dia 31/12/2018. Fonte: Autor 
Tabela 2 - Resultado da modelagem de vazões para a entrada da lagoa de detenção do Guará, antes e após calibração.

\begin{tabular}{|c|c|c|c|}
\hline \multirow{2}{*}{$\begin{array}{c}\text { Evento } \\
\text { Entrada }\end{array}$} & \multicolumn{2}{|c|}{ NSE } & \multicolumn{2}{c}{$\mathbf{R}^{2}$} \\
\cline { 2 - 4 } & Antes & Após & 0,77 \\
\hline $15 / 11 / 2018$ & 0,67 & 0,68 & 0,50 \\
\hline $08 / 12 / 2018$ & $-0,26$ & $-0,12$ & 0,78 \\
\hline $22 / 12 / 2018$ & $-0,08$ & $-0,10$ & 0,54 \\
\hline $09 / 02 / 2019$ & 0,19 & 0,19 & 0,77 \\
\hline
\end{tabular}

Realizou-se também uma verificação do evento calibrado para todo o mês de dezembro, a fim de avaliar a qualidade da modelagem para simulações contínuas. Obtiveram-se valores de NSE de 0,47 e $R^{2}$ de 0,58 para a entrada da lagoa, sendo esses resultados satisfatórios. Porém, o mesmo não foi verificado para a saída, que apesar de ter apresentado bom resultado para $\mathrm{R}^{2}(0,72)$, não representou bem o formato do hidrograma observado. A Fig. 11 apresenta os hidrogramas simulado e observado para o mês de dezembro de 2018. A Fig. 12 apresenta de forma mais detaIhada a modelagem contínua, focando no período entre 22 e 26 de dezembro de 2018.

Pelas Fig. 11 e 12, percebe-se que em alguns períodos o modelo subestimou as vazões e, em outros, as superestimou. No dia 26/12/2018, por exemplo, a vazão de pico simulada superestimou a vazão de pico observada em aproximadamente $143 \%$, enquanto no dia 22/12/2018, a vazão de pico simulada subestimou a vazão de pico observada em aproximadamente $116 \%$.

Observou-se, em geral, uma superestimação das vazões de saída e mesmo após diversas tentativas manuais de alterações do $\mathrm{CN}$ da sub-bacia da lagoa de detenção bem como alterações no armazenamento em depressões permeáveis, não se obteve sucesso na melhora do hidrograma simulado de saída. A modelagem da lagoa de detenção é complexa, pois envolve a existência de caminhos preferenciais e curtos circuitos, bem como a provável existência de volumes mortos que não contribuem efetivamente para a vazão observada na saída.

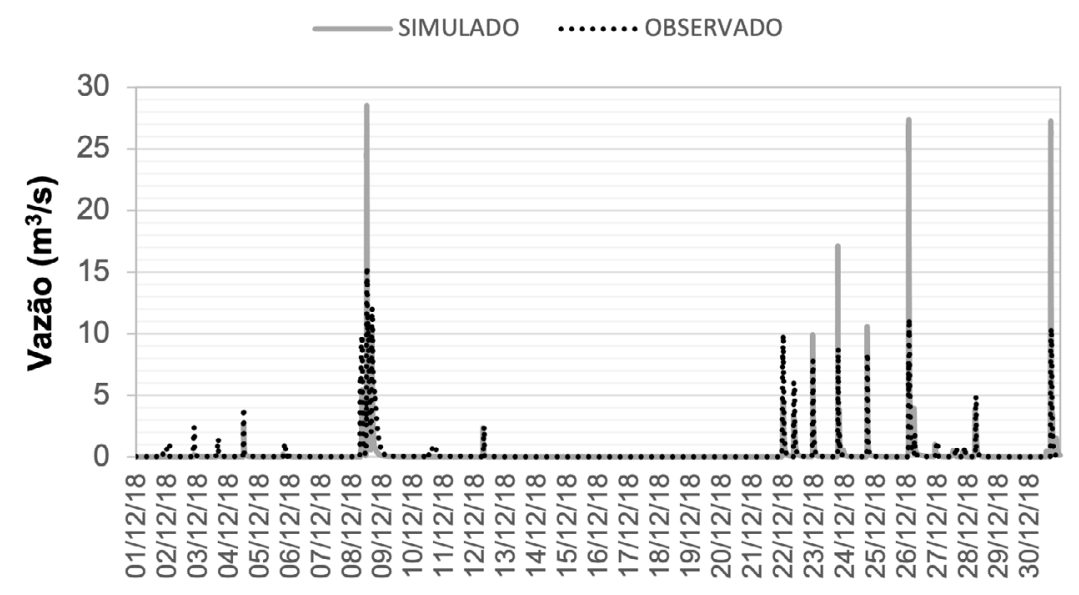

Figura 11 - Hidrogramas simulado e observado para o mês de dezembro/2018. 


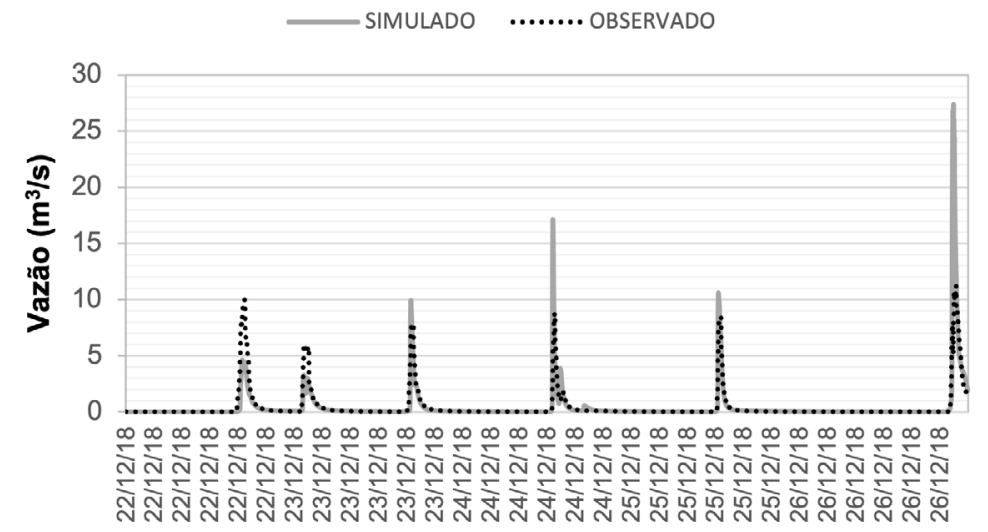

Figura 12 - Hidrogramas simulado e observado para os dias 22 a 26 de dezembro/2018. Fonte: Autor

\section{CONCLUSÕES}

O presente estudo teve por objetivo o monitoramento e a avaliação quantitativa da lagoa de detenção inserida no Parque Ezechias Heringer. Por meio do monitoramento de chuva e vazão foi possível avaliar a distribuição espacial das precipitações ocorridas na área de estudo bem como avaliar o grau de abatimento promovido pela estrutura em estudo.

A lagoa de detenção analisada, de aproximadamente 25 ha, apresentou ótimo desempenho quanto ao abatimento dos picos de vazão, observando-se um abatimento médio de 95,5\%, promovendo uma liberação gradual da água armazenada em seu interior para jusante e reduzindo os impactos provocados ao corpo hídrico receptor.

A vazão máxima de saída permitida pela Resolução $n^{\circ} 9$ da Adasa para a área de estudo é de $18,67 \mathrm{~m}^{3} \cdot \mathrm{s}^{-1}$, valor esse bem maior do que de fato é lançado pela lagoa de detenção para jusante. A partir disso, e considerando o fato de que, durante todo o período monitorado neste estudo, não se ter observado vertimento, conclui-se que a estrutura está subutilizada, sendo capaz de promover a redução das vazões de pico e mesmo a melhoria da qualidade das águas de outras áreas urbanizadas nas proximidades.

As lagoas de detenção são eficientes como medidas de controle de cheias, apresentando resul- tados satisfatórios quanto ao aspecto quantitativo, promovendo significativo abatimento das vazões de pico e reduzindo os impactos ao corpo hídrico receptor. Entretanto, sem manutenção contínua, a estrutura pode contribuir para proliferação de animais vetores de doenças e favorecer o lançamento ilegal de lixo e entulho.

Após análise do atendimento às diretrizes preconizadas na Resolução nº 9/2011, observou-se que a lagoa de detenção do Guará encontra-se superdimensionada. Esse excesso de volume poderia ser aproveitado no sentido de melhorar a qualidade das águas do escoamento superficial por meio do armazenamento das primeiras águas escoadas e mesmo o tratamento para remoção de óleos e graxas. A construção de barreiras visando ao aumento do tempo de residência do escoamento pluvial na lagoa é outra alternativa para o aproveitamento do volume excedente.

Quanto à modelagem das vazões, os resultados da verificação não foram satisfatórios. Acredita-se que as baixas eficiências na representação estejam associadas à ocorrência do remanso no interior da galeria de entrada e dificuldade, portanto, na obtenção de uma curva-chave representativa para todas as cotas e vazões, ou seja, os hidrogramas observados podem não estar representando adequadamente a realidade. Trabalhos futuros 
devem visar à modelagem adequada da vazão na galeria de entrada e na circulação e armazenamento da água na lagoa, levando em consideração a microtopografia para considerar a sedimentação e crescimento de vegetação no interior da lagoa ocorridos ao longo de mais de uma década.

\section{AGRADECIMENTOS}

Agradecemos à NOVACAP e à Adasa pela disponibilização de dados. À ANA, CAPES, FAPDF, FUNAPE e FINATEC pelo financiamento à pesquisa a qual o trabalho está inserido. À CAPES pela bolsa de mestrado. À ChiWater pela licença do PCSWMM concedida.

\section{CONTRIBUIÇÃO DOS AUTORES}

Monitoramento e coleta de dados: Paula A.C.V. e Costa M.E.L.; Conceitualização, Metodologia e Análise dos resultados Paula A.C.V., Costa M.E.L e Koide S.; Redação: Paula A.C.V.; Orientação: KoideS.

\section{REFERÊNCIAS}

ADASA, AGÊNCIA REGULADORA DE ÁGUAS, ENERGIA E SANEAMENTO BÁSICO DO DISTRITO FEDERAL - Resolução $\mathbf{n}^{\circ}$ 09, de 08 de abril de 2011. Estabelece os procedimentos gerais para requerimento e obtenção de outorga de lançamento de águas pluviais em corpos hídricos de domínio do Distrito Federal e naqueles delegados pela União e Estados.

BAPTISTA, M. B.; NASCIMENTO, N. O.; BARRAUD, S. Técnicas Compensatórias em Drenagem Urbana. 2 ed. Porto Alegre: ABRH, 2011, 318p.

BELING, F. A. Análise do desempenho do modelo SWMM5 acoplado ao calibrador PEST na bacia do Arroio Cancela/RS. Dissertação (Mestrado em Engenharia Civil), Centro de Tecnologia, Universidade Federal de Santa Maria, Santa Maria, RS, 2013, 154p.

CAMPANA, N. A.; BERNARDES, R. S.; SILVA, J. A. Controle qualitativo e quantitativo do escoamento pluvial urbano com bacias de detenção. Revista Ambiente e Água, v. 2, n. 3, 2007, p. 98-111. https://doi.org/10.4136/ambi-agua.36

CAMPOS, J. E. G. Hidrogeologia do Distrito Federal: bases para a gestão dos recursos hídricos subterrâneos. Revista Brasileira de Geociências, v. 34, n. 1, 2004, p. 41-48. https://doi. org/10.25249/0375-7536.20043414148
CANHOLI, A. P. Drenagem urbana e controle de enchentes. 2 ed. Oficina de Textos, São Paulo, 2014, 302p.

CHOW, V. T.; MAIDMENT, D. R.; MAYS, L. W. Applied Hydrology. McGraw-Hill, 1988, 572p.

ECKART, K.; MCPHEE, Z.; BOLISETTI, T. Performance and implementation of low impact development - A review. Science of the Total Environment, v. 607-608, 2017, p. 413-432. https://doi. org/10.1016/j.scitotenv.2017.06.254

GDF - Governo do Distrito Federal, Secretaria de Estado de Obras. Plano Diretor de Drenagem Urbana do Distrito Federal. Concremat Engenharia, Brasília, 2019.

HUBER, W. C.; DICKINSON, R. E. Storm Water Management Model, Version 4: User's Manual. U. S. Environmental Protection Agency, Athens, Georgia, 1992, 502p.

JAMES, W.; ROSSMAN, L. E.; JAMES, W. R. C. User's guide to SWMM5. $13^{\mathrm{a}}$ ed. CHI, Ontario, Canadá, 2010, 905p.

RIGHetTO, A. M. Manejo de Águas Pluviais Urbanas. Projeto PROSAB, Editora ABES, Rio de Janeiro, 2009, 396p.

ROSSMAN, L. A.; HUBER, W. C. Storm Water Management Model Reference Manual: Volume I - Hydrology (Revised). USEPA, Cincinnati, Ohio, 2016, 231p.

SEFIONE, A. L. Estudo comparativo de métodos de extrapolação superior de curvas-chave. Dissertação (Mestrado em Recursos Hídricos e Saneamento Ambiental), Instituto de Pesquisas Hidráulicas, Universidade Federal do Rio Grande do Sul, 2002, 240p.

SOUZA, F. P.; COSTA. M. E. L.; KOIDE, S. Hydrological modelling and evaluation of detention ponds to improve urban drainage system and water quality. Water, 11, 2019, 1547. https://doi.org/10.3390/ w11081547

TROITSKY, B.;ZHU, D.Z.; LOEWEN, M.; DUIN, B.; MAHMOOD, K. Nutrient processes and modeling in urban stormwater ponds and constructed wetlands. Canadian Water Resources Journal, v. 44, n. 3, 2019, p. 230-247. https://doi.org/10.1080/07011784.2019.1594390

TSUJI, T. M. Monitoramento e modelagem das águas de drenagem pluvial no núcleo urbano da Bacia do Ribeirão Riacho Fundo. Dissertação (Mestrado em Tecnologia Ambiental e Recursos Hídricos), Departamento de Engenharia Civil e Ambiental, Universidade de Brasília, Brasília, DF, 2018, 150p.

TSUJI, T. M.; COSTA, M. E. L.; KOIDE, S. Diffuse pollution monitoring and modelling of small urban watershed in Brazil Cerrado. Water Sci. Technol., v. 79, n. 10, 2019, p. 1912-1921. https://doi. org/10.2166/wst.2019.190

VOLKEN, N. J. Avaliação hidráulica e hidrológica de bacias de detenção: estudo de caso da bacia do Guará II - DF. Monografia (Projeto Final em Engenharia Ambiental, Departamento de Engenharia Civil e Ambiental), Universidade de Brasília, Brasília, DF, 2018, 85p. 